\title{
Local Structure and Chemistry of C-Doped ZnO@C Core-Shell Nanostructures with Room-Temperature Ferromagnetism
}

DOI:

10.1002/adfm.201704567

\section{Document Version}

Accepted author manuscript

Link to publication record in Manchester Research Explorer

Citation for published version (APA):

Ngo, D. T., Cuong, L. T., Cuong, N. H., Son, C. T., Huy, P. T., \& Dung, N. D. (2018). Local Structure and Chemistry of C-Doped ZnO@C Core-Shell Nanostructures with Room-Temperature Ferromagnetism. Advanced Functional Materials, 28(8), [1704567]. https://doi.org/10.1002/adfm.201704567

\section{Published in:}

Advanced Functional Materials

\section{Citing this paper}

Please note that where the full-text provided on Manchester Research Explorer is the Author Accepted Manuscript or Proof version this may differ from the final Published version. If citing, it is advised that you check and use the publisher's definitive version.

\section{General rights}

Copyright and moral rights for the publications made accessible in the Research Explorer are retained by the authors and/or other copyright owners and it is a condition of accessing publications that users recognise and abide by the legal requirements associated with these rights.

\section{Takedown policy}

If you believe that this document breaches copyright please refer to the University of Manchester's Takedown Procedures [http://man.ac.uk/04Y6Bo] or contact uml.scholarlycommunications@manchester.ac.uk providing relevant details, so we can investigate your claim.

\section{OPEN ACCESS}




\section{nanostructures with room-temperature ferromagnetism} and Nguyen Duc Dung, ${ }^{b, * *}$

${ }^{a}$ Electron Microscopy Centre, School of Materials, University of Manchester, Oxford Road, Manchester M13 9PL, United Kingdom

${ }^{\mathrm{b}}$ Advanced Institute of Science and Technology (AIST), Hanoi University of Science and Technology, No.1 Dai Co Viet, Hanoi, Viet Nam

* Corresponding author: duc-the.ngo@manchester.ac.uk (Duc-The Ngo)

** Corresponding author: dung.nguyenduc@ hust.edu.vn (Nguyen Duc Dung)

Keywords: diluted magnetic semiconductor; nanoparticles; transmission electron microscopy, pair distribution function, chemical bonding

\section{Abstract}

We present a superior approach to study quantitatively fine structure of $\mathrm{C}$-doped $\mathrm{ZnO}$ nanostructure using transmission electron microscopy (TEM) from which the role of carbon in $\mathrm{ZnO}$ crystal to form ferromagnetism is revealed at the first time. Electron diffraction in TEM shows Wurtzite structure in the nanoparticles with lattice parameters $(a=0.327 \pm 0.03$ $\mathrm{nm}$, and $c=0.529 \pm 0.04 \mathrm{~nm}$ ) slightly different from the original structure. Interestingly, the Zn-C bonding with a bonding length of $2.58 \AA$ is experimentally determined using atomic pair distribution function (PDF) calculated from electron diffraction data. Together with other 


\section{WILEY-VCH}

1 bonding, such as $\mathrm{C}-\mathrm{C}, \mathrm{Zn}-\mathrm{O}$ obtained from the $\mathrm{PDF}$, this demonstrates migration of $\mathrm{C}$ atoms

2 into $\mathrm{ZnO}$ crystal to substitute $\mathrm{O}$ vacancies. This is furthermore visualized by high-resolution

3 TEM image, and strongly supports the proposal of origin of ferromagnetism in the C-doped

$4 \mathrm{ZnO}$ nanoparticles where the $s-p$ and $p-p$ hybridizations formed by $\mathrm{C} 2 p-\mathrm{Zn} 4 s$, and $\mathrm{O} 2 p-$

$5 \quad \mathrm{C} 2 p$ orbitals are believed to cause ferromagnetism.

6 


\section{WILEY-VCH}

\section{Introduction}

Dilute magnetic semiconductors (DMSs), such as Mn-doped $\mathrm{ZnO},{ }^{[1]} \mathrm{Co}$-doped $\mathrm{ZnO},{ }^{[2]}$ GaMnAs, ${ }^{[3]} \mathrm{Cr}$-doped AlN,${ }^{[4]}$ etc. are desired candidates for spintronic applications. DMSs are commonly synthesized by doping non-magnetic semiconductor with several atomic per cent of transition metal (TM) elements to create ferromagnetism. ${ }^{[5]}{ }^{[6]}$ Creating ferromagnetism in zinc oxide ( $\mathrm{ZnO})$, a well-known II-VI semiconductor, has attracted much attention due to its abundance, low environment impact, wide bandgap (3.3 eV) and high exciton binding energy. ${ }^{[7]}$ Room temperature ferromagnetism in $\mathrm{ZnO}$ has been observed by doping the material with $3 d$ metals, such as, $\mathrm{Fe}, \mathrm{Co}, \mathrm{Mn},{ }^{[2]}$ and $\mathrm{Cu}^{\left[{ }^{[8]}\right.}$ However, $3 d \mathrm{TM}$ doping of $\mathrm{ZnO}$ also produced unwanted second phase precipitation, which may result in unpredicted properties and limits the practical applications of such materials. ${ }^{[9]}$

A number of theoretical studies have proposed the use of non-TM doping elements to create magnetism in $\mathrm{ZnO}$, without the problem of second phase precipitation. ${ }^{[9-13]}$ These papers predict that elements like carbon, could be substituted at an anion site to develop a spin polarised solution in $\mathrm{ZnO}{ }^{[9]}$ Experimental demonstration of ferromagnetism above room temperature has already been demonstrated for doping by carbon, ${ }^{[14-16]}$ boron, ${ }^{[17,18]}$ and potassium, ${ }^{[19]}$. C-doped $\mathrm{ZnO}$ nanostructures are particularly a attractive because of this dopant is cheap, safe and abundant. ${ }^{[20][14-16]}$ It has been demonstrated that carbon doping could result in a new energy state in the band gap as well as oxygen vacancies in $\mathrm{ZnO}$ lattice that might be responsible for the visible photoactivity of $\mathrm{C}$-doped $\mathrm{ZnO}{ }^{[21]}$ These make C-doped $\mathrm{ZnO}$ nanostructures an excellent candidate for opto-spintronic applications. ${ }^{[22]}$

In previous work, ${ }^{[23]}$ we demonstrated strong ferromagnetism above room temperature in sol-gel synthesized $\mathrm{C}$-doped $\mathrm{ZnO}$ nanoparticles. Co-existence of different magnetic phases in the materials was experimentally demonstrated by means of magnetometric measurements. Xray photoelectron spectroscopy (XPS) revealed the presence of $\mathrm{Zn}-\mathrm{C}$, O-C and C-C bonds at 


\section{WILEY-VCH}

1 the surface of $\mathrm{C}$-doped $\mathrm{ZnO}$ nanoparticles but which could not be detected by refinement of

2 X-ray diffraction data. The suggests that the $\mathrm{C}$ substitution in the $\mathrm{ZnO}$ structure only occurs

3 on the surface of $\mathrm{ZnO}$ nanoparticles but no direct experimental evidence has confirmed this

4 hypothesis. Here we present a deeper investigation to determine the local structure and

5 chemistry of $\mathrm{C}$-doped $\mathrm{ZnO}$ nanoparticles using transmission electron microscopy to better

6 understand the origin of the observed room-temperature ferromagnetism. For the first time,

7 we quantitatively demonstrate the existence of $\mathrm{Zn}-\mathrm{C}, \mathrm{C}-\mathrm{C}$ bonding in the $\mathrm{ZnO}$ nanostructures, revealing the ability of $\mathrm{C}$ to substitute intoO vacancies.

\section{Experimental details}

$\mathrm{ZnO}$ nanoparticles were prepared by sol-gel method from a solution of zinc acetate and diethanolamine (DEA) in isopropanol. Carbon doping was produced by thermal treatment at $450^{\circ} \mathrm{C}$ in Ar with $\mathrm{C}$ additive. Further details of materials preparation can be found in ref. ${ }^{[23]}$

Morphology, structure and elemental chemistry of the materials were investigated using transmission electron microscopy (TEM) in a FEI Tecnai F30 equipped with a field emission gun (FEG) and high-angle annular dark field (HAADF) detector for scaning TEM (STEM) imaging, and a FEI Talos F200A AEM with Ultrahigh brightness SuperX FEG (200 kV). Chemical analysis was performed by an energy dispersive X-ray spectroscopy (EDS) in the TEM (the FEI Talos F200A) using SuperX silicon drift detectors (SSDs) built-in the pole piece of the objective lens for high-resolution and high-precision elemental mapping. Chemical analysis was also further conducted by energy-filtering TEM (EFTEM) in FEI Tecnai F30 using a post column Gatan Imaging Filter (GIF). Indexing of the selected area diffraction patterns was performed using the CrysTBox software. ${ }^{[24]}$ The magnetization of the materials was measured by MicroSence EZ9 vibrating sample magnetometer (VSM). 


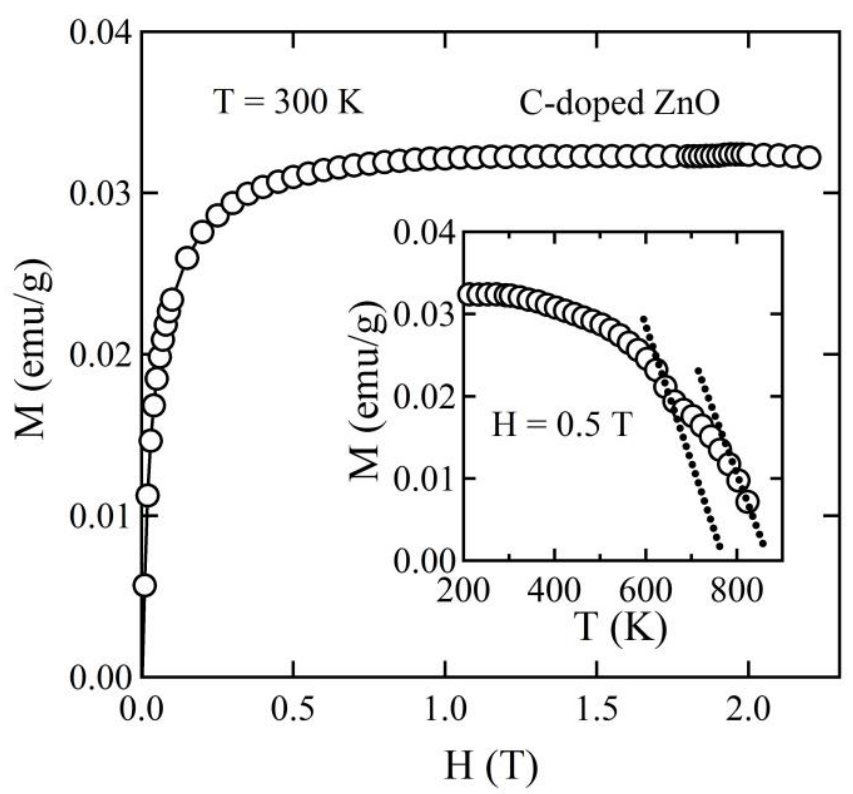

Figure 1. Magnetization curve of the $\mathrm{C}$-doped $\mathrm{ZnO}$ nanoparticles measured at room temperature $T=300 \mathrm{~K}$. The inset shows temperature dependence of magnetisation of the sample measured in an applied field of $0.5 \mathrm{~T}$.

Figure 1 presents a virgin magnetization $(M-H)$ curve of the $\mathrm{C}$-doped $\mathrm{ZnO}$ nanoparticles obtained at room temperature $(T=300 \mathrm{~K}$. The sample shows ferromagnetic behaviour with two magnetization processes including magnetic moments rotation and magnetic metastable phase transition. ${ }^{[23]}$ The magnetization is observed to saturate when the applied magnetic field is larger than about $0.5 \mathrm{~T}$. The saturation magnetization of the $\mathrm{C}$-doped $\mathrm{ZnO}$ sample is about 5-6 times larger that in undoped $\mathrm{ZnO}$ nanoparticles reported previously. ${ }^{[25]}$ The thermomagnetic $(M-T)$ curve shown inset in Fig. 1 demonstrates two phase transition Curie temperatures, $T_{C}$, in the at temperature ranges of $780-800 \mathrm{~K}$ and $860-880 \mathrm{~K}$ respectively. These likely correspond to two different ferromagnetic phases in the sample with different exchange energies. The presence of more than one ferromagnetic phases in these materials may explain why previous reports have found different values for the Curie points in similar materials. ${ }^{[26,27]}$ It could also be assumed that such two magnetic phases belong separately to the two types of $\mathrm{ZnO}$ nanocrystal morphology. As the discussion in previous work ref. ${ }^{[23]}$, the original mechanism of ferromagnetism of $\mathrm{C}$-doped $\mathrm{ZnO}$ presumably comes from two causes: the defects of the $\mathrm{ZnO}$ crystalline structure and the substitution of $\mathrm{C}$ atoms at $\mathrm{O}$ sites in $\mathrm{ZnO}$ 


\section{WILEY-VCH}

1 Wurtzite crystalline structure to create $\mathrm{Zn}-\mathrm{C}$ bonding. The studies of morphology, crystalline

2 structure and the doping of $\mathrm{C}$ into $\mathrm{ZnO}$ crystalline lattices will provide more information on

3 the mechanism of ferromagnetic properties in the $\mathrm{ZnO}$ material systems. Based on high

4 resolution transmission electron microscopy (HRTEM, EFTEM) imaging as well as electron

5 diffraction and energy dispersive X-ray spectroscopy (EDS) mapping, the studied results are

6 discussed in detail in the following.

7 The bright-field (BF) TEM images of the C-doped $\mathrm{ZnO}$ nanoparticles ( Figure 2a) shows 8 that these have a spherical morphology with a diameter of 80-120 nm. Magnified BF TEM

9 and high-resolution TEM (HRTEM) images [Fig. 2(b,c)] reveal a core-shell structure where a

10 crystalline core is surrounded by an amorphous shell [Fig. 2(c)]. Analysis of selected area

11 electron diffraction (SAED) patterns averaging over many nanoparticles [Fig. 2(d)] indicate a

12 Wurtzite hexagonal crystal structure with lattice parameters $a=0.327 \pm 0.03 \mathrm{~nm}$, and $c=$

$130.529 \pm 0.04 \mathrm{~nm}$. This gives a $c / a$ ratio of 1.62 , slightly lower than that in the original $\mathrm{ZnO}$

14 Wurtzite nanoparticles where $c / a \approx 1.60$. Lattice parameters obtained by analysing HRTEM

15 images of the crystalline core in Fig. 2(c) are consistent with the SAED data. 


\section{WILEY-VCH}
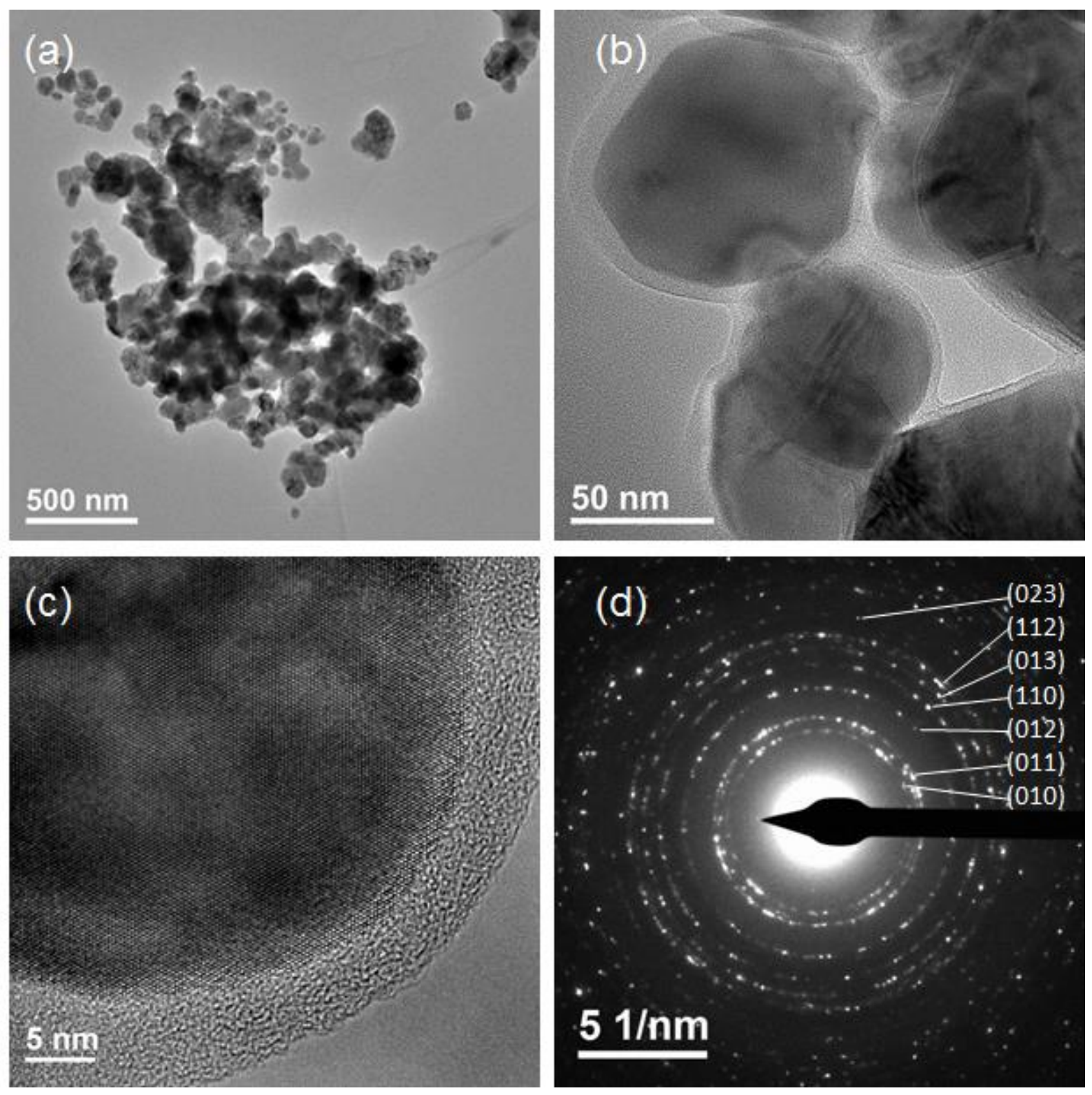

2 Figure 2. TEM images of the $\mathrm{C}$-doped $\mathrm{ZnO}$ nanoparticles: (a) low-magnification bright-field TEM image, (b)

3 magnified BF TEM image from a small area in (a), (c) HRTEM image of an individual nanoparticle in (a), and

4 (d) indexed SAED pattern.

5 In addition to SAED analysis, the crystal structure of the individual C-doped $\mathrm{ZnO}$

6 nanoparticle was also measured with high precision using convergent beam electron

7 diffraction (CBED). Using a microprobe STEM allignment, a STEM-HAADF image of the

8 nanoparticle cluster was firstly acquired [Fig. 3(a)] then the electron beam was focussed on an

9 individual particle to generate the CBED pattern [Fig. 3(b)]. The pattern is a good fit to with

10 the Wurtzite $\mathrm{ZnO}$ structure viewed along the [121] crystal zone axis with the lattice parameters 


\section{WILEY-VCH}

1 determined as $a=0.326 \pm 0.02 \mathrm{~nm}$, and $c=0.530 \pm 0.02 \mathrm{~nm}$, in excellent agreement with our

2 SAED measurements.. Furthermore, local lattice strain could be observed from the dark

3 fringes in the CBED disks (Supporting Information, S1). ${ }^{[28]}$
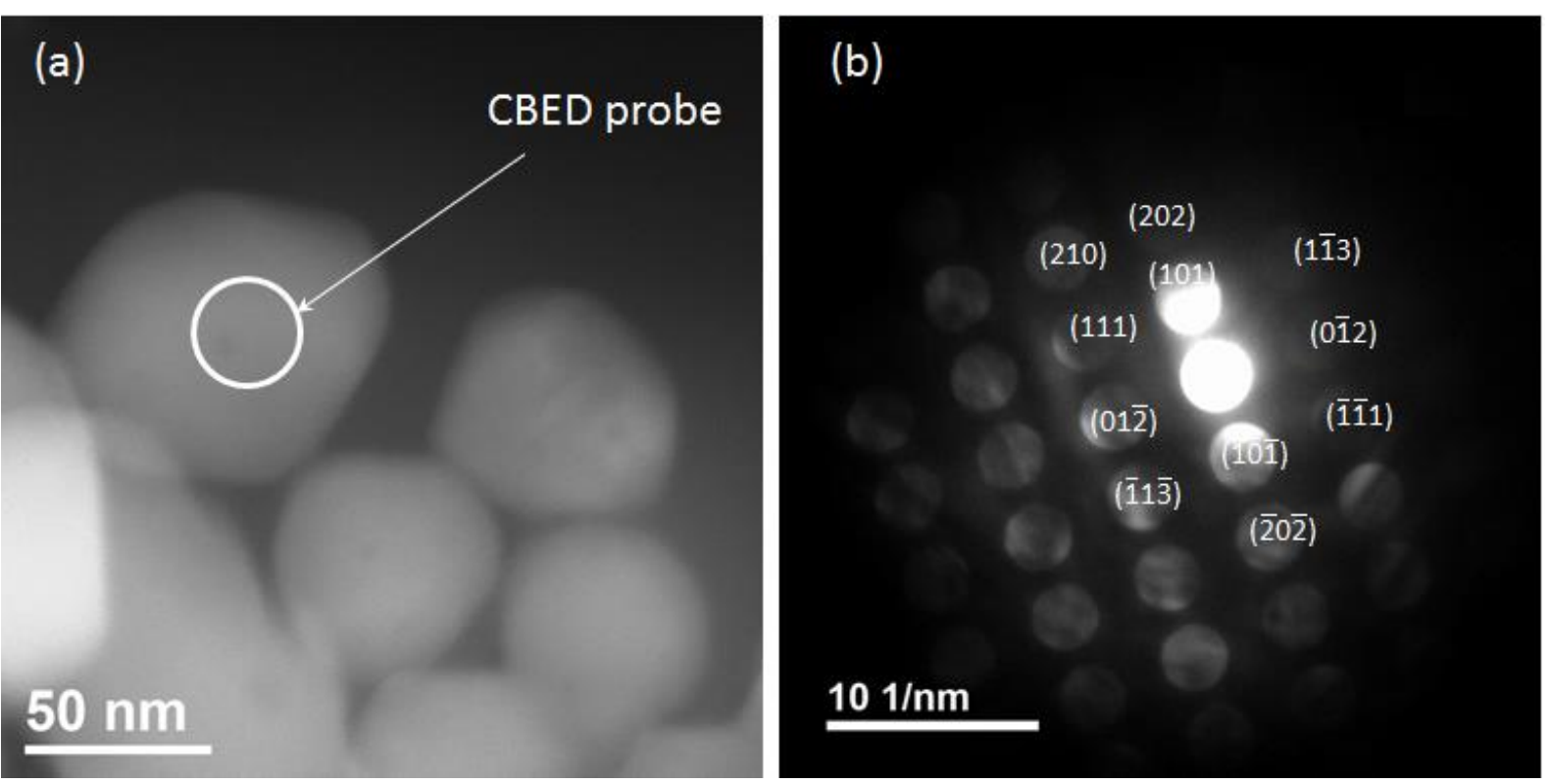

5 Figure 3. (a) STEM-HAADF image of $\mathrm{C}$-doped $\mathrm{ZnO}$ nanoparticles, (b) a CBED pattern of the C-doped $\mathrm{ZnO}$

6 nanoparticle indicated by the white circle in (a). The electron beam was parallel to the [i21] zone axis of the $\mathrm{ZnO}$ 7 crystal.

8 In order to probe the local disorder of the $\mathrm{C}$-doped $\mathrm{ZnO}$ nanoparticles a pair distribution

9 function (PDF) analysis was performed on the SAED data to quantify the bond lengths

10 between atoms. To achieve this a total scattering intensity profile of the diffraction pattern

11 was first obtained from the SAED image by rotationally averaging. The PDF can then be

12 derived using SUePDF software based on kinematical electron scattering theory as well as the

13 total scattering methodology. ${ }^{[29]}$ The PDFs reconstructed after Fourier transformation are

14 normalised with respect to number density, nanoparticle form factor and with the requirement

15 of non-negativity of the probability density. ${ }^{[29]}$ 


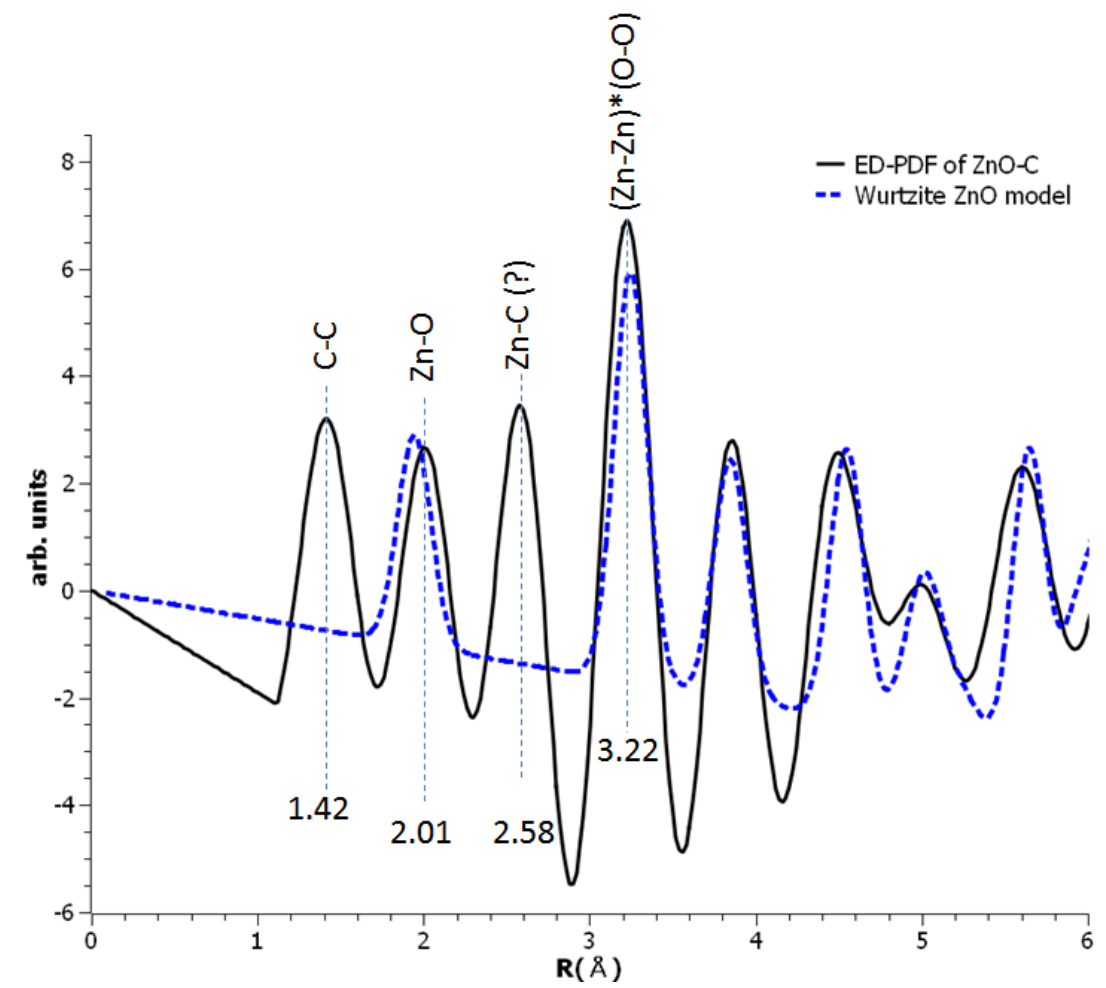

Figure 4. Electron diffraction PDF of C-doped $\mathrm{ZnO}$ nanoparticles (dark solid line plot) compared with PDF of original Wurtzite structure calculated from $\mathrm{ZnO}$ single crystal data. ${ }^{[30]}$

Bond lengths in the material can be inferred from the position peaks in the $\operatorname{PDF}^{[29,31]}$ Fig. 4 illustrates the PDF for our C-doped $\mathrm{ZnO}$ nanoparticles compared with pure Wurtzite $\mathrm{ZnO}$ calculated from a $\mathrm{ZnO}$ single crystal model. ${ }^{[30]}$ The PDF of the C-doped $\mathrm{ZnO}$ nanoparticles showspeaks that can be associated with Zn-O bonding (@ 2.01 ), and with Zn-Zn or O-O bonding (@3.22 $\AA$ ) in the Wurtzite structure. A small increase is observed for the Zn-O bond length in our C-doped ZnO PDF (2.01 ̊) compared to that of the single crystal Wurtzite ZnO structure $(1.98 \AA)$, most likely due to a slight difference in the lattice parameters of the two materials. This is consistent with previous reports where $\mathrm{Zn}-\mathrm{O}$ bond lengths in $\mathrm{ZnO}$ nanoparticles varied from $1.96 \AA$ to $2.06 \AA$ depending on particle size and doping ${ }^{[32]}$.

4 Importantly the PDF of the C-doped $\mathrm{ZnO}$, also shows new peaks at $1.42 \AA$ and $2.58 \AA$. 5 The peak at $1.42 \AA$ is a good match to the C-C intraplanar bond length in graphene and is likely associated with carbon on the surface of the particle. ${ }^{[33]}$ However the peak at $2.58 \AA$ is 


\section{WILEY-VCH}

1 believed to be due to the presence of $\mathrm{Zn}-\mathrm{C}$ bonds in the material. An X-ray diffraction study

2 by Ruccolo et al. indicated that $\mathrm{Zn}-\mathrm{C}$ bond lengths vary between 2.17 and $2.68 \AA$ depending

3 on the compounds. ${ }^{[34]}$ Zhanpeisov et al. theoretically found a bond length of $2.381 \AA$ for Zn-C

4 bonding on the surface of $\mathrm{ZnO}$ adsorped with carbon monoxide. ${ }^{[35]}$ In addition, Sharma and

5 Singh theoretically predicted that when $\mathrm{C}$ atoms were doped into $\mathrm{ZnO}$ clusters, interstitial $\mathrm{C}$

6 atoms showed a preference to bond with $\mathrm{Zn}$ atoms with a bond length between 2.2-2.5.$^{[36]}$.

7 The relatively high bond length found for $\mathrm{Zn}-\mathrm{C}$ (within the predicted range) suggests that $\mathrm{C}$

8 atoms are substituting into $\mathrm{O}$ lattice sites in the $\mathrm{ZnO}$ Wurtzite crystal rather than being

9 associated with the surface. This is in agreement with experimental results from XPS analysis

10 reported by Pan et al. ${ }^{[26]}$

11 According to Nayak and co-workers, ${ }^{[13]}$ although substitution of $\mathrm{C}$ for $\mathrm{O}$ is less is 12 energetically favourable that that for $\mathrm{Zn}$, it could be stabilized under specific growth 13 conditions ( $\mathrm{O}$ e.g. poor and $\mathrm{C}$ rich growth condition) which are similar to those used to 14 synthesis our nanoparticles. Furthermore, they predict that $\mathrm{C}$ substituted into $\mathrm{O}$ vacancies 15 would be associated with a localized magnetic moment of $2 \mu_{\mathrm{B}} /$ atom $(\mathrm{C}) .{ }^{[13]}$ This is because 16 when the carbon atom is substitutes for the $\mathrm{O}$ site in the $\mathrm{ZnO}$ lattice, it has a zinc atom as the

17 first nearest neighbour and an oxygen atom as the second nearest neighbour, and as a result, 18 magnetism would result from $\mathrm{ZnC}, \mathrm{Zn}_{2} \mathrm{C}, \mathrm{Zn}_{2} \mathrm{OC}$, and $\mathrm{Zn}_{2} \mathrm{C}_{2}$ clusters. ${ }^{[10]}$ It should be noted that the exchange energy is sensitive to the dimensionality of the clusters and it is believed to be highest for three-dimensional clusters. Sharma et al. ${ }^{[36]}$ found that the eigenvalues for $2 p$

21 orbitals of $\mathrm{C}$ atoms and $4 s$ orbitals of $\mathrm{Zn}$ atoms were relatively close to each other for spin up22 states, whereas the spin down eigenvalue of the $\mathrm{C}$ atoms' $2 p$ orbital was significantly higher than the $\mathrm{Zn} 4 s$. The $s-p$ hybridization formed by $\mathrm{C} 2 p$ and $\mathrm{Zn} 4 s$ orbitals, as well as the splitting

24 of the up and down energy levels exists for all the $\mathrm{C}$-doped $\mathrm{ZnO}$ systems result in the 25 formation of a magnetic moment localized on the carbon atoms due to the doubly degenerate 


\section{WILEY-VCH}

1 pure $p$ states. ${ }^{[36]}$ Experimental work based on XPS and Auger spectroscopy by Li et al. ${ }^{[37]}$ on

2 C-doped $\mathrm{ZnO}$ films also supported the proposed $s-p$ hybridization.

3 In addition, Pan et al. ${ }^{[26]}$ have predicted that substitution of $\mathrm{C}$ atoms at $\mathrm{O}$ sites in $\mathrm{ZnO}$

4 crystals created holes in the $\mathrm{O} 2 p$ states coupling with the parent $\mathrm{C} 2 p$ localized spins by a $p-p$

5 interaction which was similar to $p$ - $d$ hybridization in TM-doped semiconductors or oxides.

6 Such a $p-p$ interaction resulted in the appearance of additional mixed band levels originating

7 from the valence band. The $\mathrm{O} 2 p-\mathrm{C} 2 p$ coupling was believed to push the minority $\mathrm{p}-\mathrm{p}$ mixed state upward and the opposite spin state downward causing a reduction in the total energy of the system. The wave function of the $\mathrm{C} 2 p$ states was found to extend spatially to neighbouring $\mathrm{O} 2 p$ states, and couple to these. Therefore, holes reportedly aligned the spin of parent $\mathrm{C}$ atoms

11 to cause an indirect ferromagnetic coupling of $\mathrm{C}$ atoms. Interestingly, the $p-p$ interaction is 12 relatively long range, ${ }^{[38,39]}$ which explains the strong ferromagnetism behaviour in $\mathrm{ZnO}$ 13 induced even at low doping concentrations. An anomalous Hall effect measurement 14 conducted on $\mathrm{C}$-doped $\mathrm{ZnO}$ nanoneedles by Herng et al. ${ }^{[14]}$ experimentally supported this hypothesis by demonstrating the role of $p$-type conduction (locallised holes) in the magnetotransport properties of the material. These theoretical calculations and our new experimental evidence of $\mathrm{Zn}-\mathrm{C}$ bonding supports the proposed mechanism of ferromagnetism in non-TM doped $\mathrm{ZnO}$ nanostructures in which hybridization of $p-p(\mathrm{O} 2 p-\mathrm{C} 2 p$ interaction) and $s-p(\mathrm{Zn} 4 s-\mathrm{C} 2 p)$ orbitals play a crucial role to produce long range ferromagnetic behaviour.

In fact, the $\mathrm{Zn}-\mathrm{C}$ bonding was qualitatively confirmed in our previous study using XPS analysis which is sensitive to the surface effect but could not be detected by refinement of Xray diffraction. It suggests that the $\mathrm{C}$ occupation in the $\mathrm{ZnO}$ structure only occurs on the surface of $\mathrm{ZnO}$ nanoparticles. This proposal could be clarifed by elemental mapping using STEM-EDS presented in the following paragraph. 


\section{WILEY-VCH}
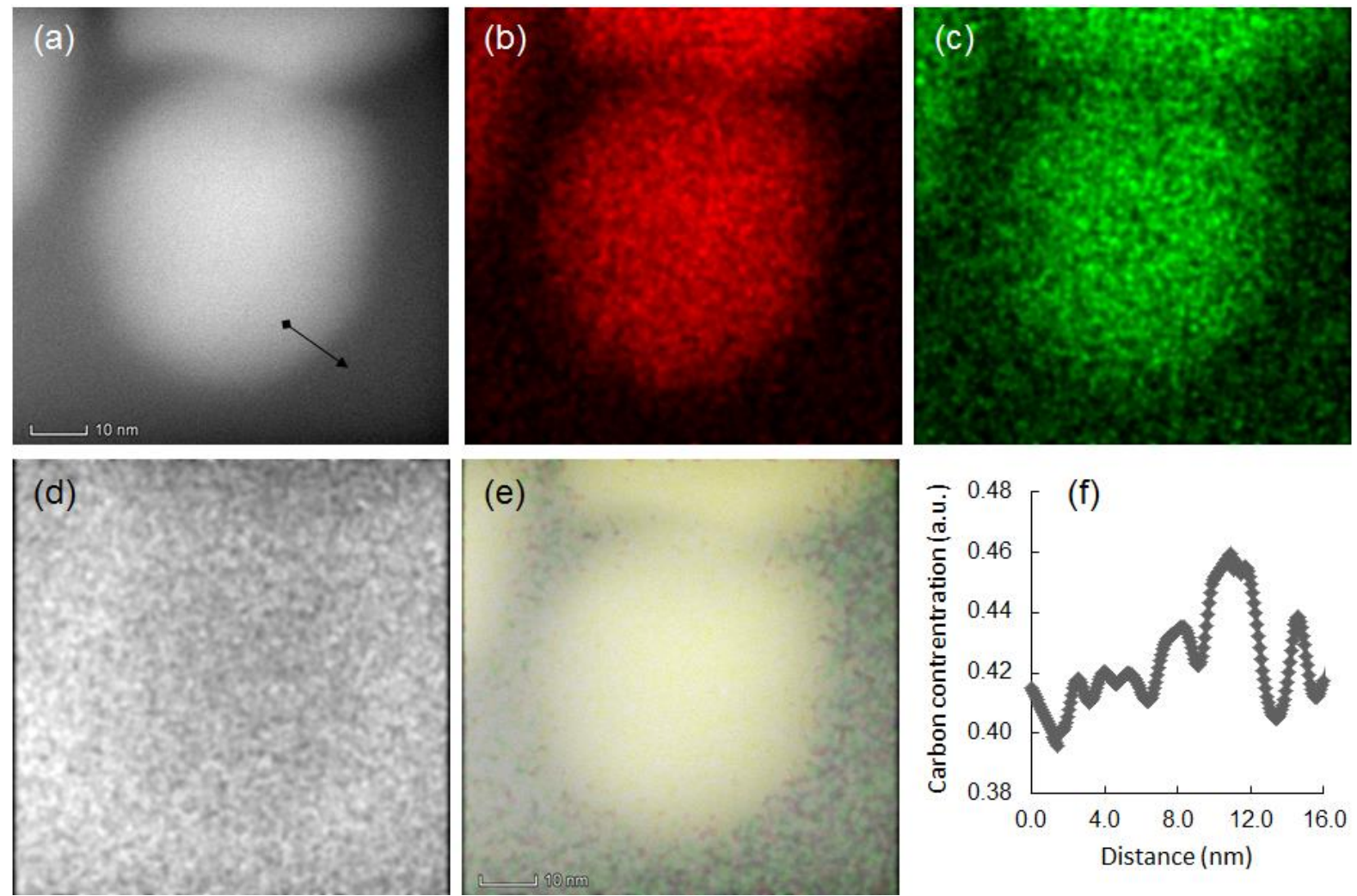

Figure 5. (a) STEM-HAADF image of a C-doped ZnO nanoparticle, (b,c,d) STEM-EDS elemental maps of Zn,

$\mathrm{O}$ and $\mathrm{C}$ obtained from the area in (a), (e) a mixture map of $\mathrm{Zn}, \mathrm{O}$ and $\mathrm{C}$, and (f) a line profile shows how concentration of carbon varies through the edge of the crystalline core along the dark line on the HAADF image (a).

Fig. 5 presents a high-resolution elemental mapping of the $\mathrm{C}$-doped $\mathrm{ZnO}$ nanoparticles using STEM-EDS performed on the FEI Talos F200A. The crystalline $\mathrm{ZnO}$ particle is observed in the HAADF image [Fig. 5(a)] as a bright-contrast particle on the dark background.

9 Elemental maps of $\mathrm{Zn}, \mathrm{O}$ and $\mathrm{C}$ are also constructed [Fig. 5(b.c.d)] from which a distribution of carbon through the edge of the crystalline core is plotted in Fig. 5(f). It could be seen that

11 the concentration of carbon goes through a maximum peak within a thickness of 2-3 nm [Fig.

$125(f)]$ to prove the above assumption that carbon doping only occcurs in a certain depth on the surface of the $\mathrm{ZnO}$ crystal. Although this variation could be seen in the EDS line distribution

14 such a variation is weak to observe on the elemental map. It could also somehow seen in the HRTEM image a thin crystalline layer (visible as lattice fringes in the HRTEM image - 


\section{WILEY-VCH}

1 Supporting information, S2) with brighter contrast arised from lower-weight atoms than the

2 inner atomic column.

3 It is worth noting that this effect only occurs on the surface of the nanoparticles at a few-

4 nanometre depth thus it could be hardly detectable using macroscopic measurements such as

5 X-ray diffraction or magnetometric measurement. XPS is a suface-sensitive technique ${ }^{[40]}$ to

6 detect this effect but quantitative measurement of bond length using XPS would be a

7 challenge. Therefore, it is emphasized that extraction of chemical bond length by obtaining

8 the PDF from TEM diffraction data could be considered a simple but superior quantitative

9 approach.

10

11

12
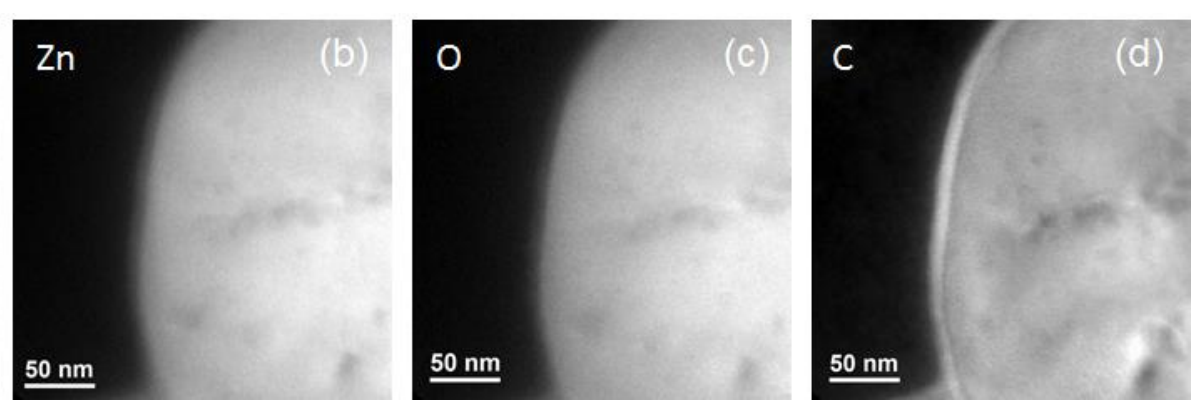

Figure 6. EFTEM images of a C-doped $\mathrm{ZnO}$ nanoparticle: (a) BF-TEM image, (b-d) EFTEM elemental maps ( $\mathrm{Zn}, \mathrm{O}$ and $\mathrm{C}$ ) from the particle in BF-TEM image.

EFTEM elemental mapping of a single nanoparticle reveals that the amorphous shell is enriched in carbon compared to the crystalline core, although small quantities of both $\mathrm{Zn}$ and $\mathrm{O}$ are found to be associated with the shell (Fig. 6). This compositional analysis is confirmed by STEM-EDS elemental mapping presented in Supporting Information (S3). We hypothesise that the $\mathrm{Zn}-\mathrm{O}-\mathrm{C}$ amorphous shell formed on the nanoparticle surface during high temperature heat treatment. The amorphous shell may play a role in the optical properties (e.g. photoluminescence $)^{[41]}$ but, to the best of our knowledge, an amorphous surface structure such as this is not able to create the observed ferromagnetic behaviour we observe.Thus we predict that $\mathrm{C}$ atoms are able to diffuse into the crystalline core from the shell and substitute for the $\mathrm{O}$ to form C-doped $\mathrm{ZnO}$. Therefore, further understanding the role of carbon would be needed 


\section{WILEY-VCH}

1 to tailor the materials structure and properties, and TEM characterisation, such as, electron

2 energy loss spectroscopy (EELS), ${ }^{[42,43]}$ would be the state-of-the-art approach to fullfil this 3 thirst.

\section{Conclusions}

In conclusion, we demonstrated a quantitative analysis of bonding in $\mathrm{C}$-doped $\mathrm{ZnO}$ nanocrystals from TEM electron diffraction data in order to better understand the ferromagnetism above room temperature. For the first time, a bond length of $2.58 \AA$ has been experimentally determined for $\mathrm{Zn}-\mathrm{C}$ bonding indicating the presence of $\mathrm{C}$ atoms substituted for $\mathrm{O}$ vacancies in the $\mathrm{ZnO}$ lattice. This is expected to occur on the surface of the doped $\mathrm{ZnO}$ nanocrystals and is ascribed to the origin of room temperature ferromagnetism due to $\mathrm{s}-\mathrm{p}$ hybridization formed by $\mathrm{C} \mathrm{p}$ and $\mathrm{Zn} 4 \mathrm{~s}$ orbitals, and $p-p$ hybridization formed by $\mathrm{O} p$ and $\mathrm{C} p$ orbitals. A C-rich amorphous shell coating on $\mathrm{ZnO}$ has also been revealed using EFTEM and HRTEM imaging. We emphasize our approach to extract the bond length from TEM diffraction data is a simple technique which is particularly useful for nanoparticulate systems where XRD measurements fail and is highly complementary to XPS measurements of chemical state.

\section{Acknowledgements}

We would like to thank Dr. Dung Trung Tran (Johnson Matthey Technology Centre) for fruitful discussions and comments on analysing electron diffraction data. This research is funded by Vietnam National Foundation for Science and Technology Development (NAFOSTED) under grant number 103.01-2011.54. Nice comments and suggestions by Dr. Sarah Haigh (University of Manchester) are highly appreciated. 


\section{WILEY-VCH}

Received: ((will be filled in by the editorial staff))

2

Revised: ((will be filled in by the editorial staff))

3

Published online: ((will be filled in by the editorial staff))

4 


\section{WILEY-VCH}

1 References

2 [1] P. Sharma, A. Gupta, K. V Rao, F. J. Owens, R. Sharma, R. Ahuja, J. M. O. Guillen, B. Johansson, G. a Gehring, Nat. Mater. 2003, 2, 673.

4 [2] K. Ueda, H. Tabata, T. Kawai, Appl. Phys. Lett. 2001, 79, 988.

5 [3] H. Ohno, Science (80-. ). 1998, 281, 951.

6 [4] D. Kumar, J. Antifakos, M. G. Blamire, Z. H. Barber, Appl. Phys. Lett. 2004, 84, 5004.

7 [5] W. Prellier, A. Fouchet, B. Mercey, J. Phys. Condens. Matter 2003, 15, 1583.

8 [6] S. A. Chambers, B. Gallagher, New J. Phys. 2008, 10, 55004.

9 [7] T. Dietl, H. Ohno, Rev. Mod. Phys. 2014, 86, 187.

10 [8] D. B. Buchholz, R. P. H. Chang, J. Y. Song, J. B. Ketterson, Appl. Phys. Lett. 2005, 87, 11 82504.

12

[9] A. El-Amiri, H. Lassri, E. K. Hlil, M. Abid, J. Magn. Magn. Mater. 2015, 374, 338.

[10] B. J. Nagare, S. Chacko, D. G. Kanhere, J. Phys. Chem. A 2009, 144, 2689.

[11] H. Wu, A. Stroppa, S. Sakong, S. Picozzi, M. Scheffler, P. Kratzer, Phys. Rev. Lett. 2010, 105, 2.

[12] A. Pham, M. H. N. Assadi, Y. B. Zhang, a. B. Yu, S. Li, J. Appl. Phys. 2011, 110, 123917.

[13] S. K. Nayak, M. E. Gruner, S. Sakong, S. Sil, P. Kratzer, S. N. Behera, P. Entel, Phys. Rev. B 2012, 86, 1.

[14] T. S. Herng, S. P. Lau, C. S. Wei, L. Wang, B. C. Zhao, M. Tanemura, Y. Akaike, Appl. Phys. Lett. 2009, 95, 2009.

[15] H. Kwak, J. R. Chelikowsky, Appl. Phys. Lett. 2009, 95, 263108.

[16] X. Zhang, J. Qin, R. Hao, L. Wang, X. Shen, R. Yu, S. Limpanart, M. Ma, R. Liu, J. Phys. Chem. C 2015, 119, 20544.

[17] S. Yilmaz, J. Nisar, Y. Atasoy, E. McGlynn, R. Ahuja, M. Parlak, E. Bacaksiz, Ceram. Int. 2013, 39, 4609. 


\section{WILEY-VCH}

1 [18] M. H. Farooq, X.-G. Xu, H.-L. Yang, C.-J. Ran, J. Miao, M. Z. Iqbal, Y. Jiang, Rare Met. 2013, 32, 264.

[19] R. Krithiga, S. Sankar, V. Arunkumar, J. Supercond. Nov. Magn. 2015, 245.

[20] S. Cho, J.-W. Jang, J. S. Lee, K.-H. Lee, CrystEngComm 2010, 12, 3929.

[21] A. S. Alshammari, L. Chi, X. Chen, A. Bagabas, D. Kramer, A. Alromaeh, Z. Jiang, $R S C A d v$. 2015, 5, 27690.

[22] Z. Dai, A. Nurbawono, A. Zhang, M. Zhou, Y. P. Feng, G. W. Ho, C. Zhang, J. Chem. Phys. 2011, 134, 104706.

[23] N. D. Dung, C. T. Son, P. V. Loc, N. H. Cuong, P. T. Kien, P. T. Huy, N. N. Ha, J. Alloys Compd. 2016, 668, 87.

[24] M. Klinger, A. Jager, J. Appl. Crystallogr. 2015, 48, 2012.

[25] M. A. Garcia, J. M. Merino, E. F. Pinel, A. Quesada, J. De La Venta, M. L. R. González, G. R. Castro, P. Crespo, J. Llopis, J. M. González-Calbet, A. Hernando, Nano Lett. 2007, 7, 1489.

[26] H. Pan, J. B. Yi, L. Shen, R. Q. Wu, J. H. Yang, J. Y. Lin, Y. P. Feng, J. Ding, L. H. Van, J. H. Yin, Phys. Rev. Lett. 2007, 99, 127201.

[27] F. B. Zheng, C. W. Zhang, P. J. Wang, H. X. Luan, J. Appl. Phys. 2012, 111, 44329.

[28] A. Béché, J. L. Rouvière, J. P. Barnes, D. Cooper, Ultramicroscopy 2013, 131, 10.

[29] D. T. Tran, G. Svensson, C. W. Tai, J. Appl. Crystallogr. 2017, 50, 304.

[30] H. Sawada, R. Wang, A. W. Sleight, J. Solid State Chem. 1996, 122, 148.

[31] R. B. Neder, V. I. Korsunskiy, J. Phys. Condens. Matter 2005, 17, S125.

[32] T. Liu, H. Xu, W. S. Chin, Z. Yong, A. T. S. Wee, J. Phys. Chem. C 2008, 112, 3489.

[33] L. Brockway, L. Pauling, J. Am. Chem. Soc. 1937, 59, 1223.

[34] S. Ruccolo, W. Sattler, Y. Rong, G. Parkin, J. Am. Chem. Soc. 2016, 138, 14542.

[35] N. U. Zhanpeisov, G. M. Zhidomirov, M. Baerns, J. Struct. Chem. 1994, 35, 9.

[36] H. Sharma, R. Singh, J. Phys. Condens. Matter 2011, 23, 106004. 


\section{WILEY-VCH}

1 [37] X. L. Li, J. F. Guo, Z. Y. Quan, X. H. Xu, G. A. Gehring, IEEE Trans. Magn. 2010, 46,

2

3

4

5

6

7

8

9

10

11

12

13

14

15

16 1382.

[38] J. Lee, N. G. Subramaniam, I. A. Kowalik, J. Nisar, J. Lee, Y. Kwon, J. Lee, T. Kang, X. Peng, D. Arvanitis, R. Ahuja, Sci. Rep. 2015, 5, 17053.

[39] G. Z. Xing, Y. H. Lu, Y. F. Tian, J. B. Yi, C. C. Lim, Y. F. Li, G. P. Li, D. D. Wang, B. Yao, J. Ding, Y. P. Feng, T. Wu, AIP Adv. 2011, 1, 22152.

[40] D. R. Baer, D. J. Gaspar, P. Nachimuthu, S. D. Techane, D. G. Castner, Anal. Bioanal. Chem. 2010, 396, 983.

[41] N. Tu, K. T. Nguyen, D. Q. Trung, N. T. Tuan, V. N. Do, P. T. Huy, J. Lumin. 2016, $174,6$.

[42] B. D. Yuhas, D. O. Zitoun, P. J. Pauzauskie, R. He, P. Yang, Angew. Chemie - Int. Ed. 2006, 45,420 .

[43] E. S. Cho, A. M. Ruminski, S. Aloni, Y.-S. Liu, J. Guo, J. J. Urban, Nat. Commun. 2016, 7, 10804. 